Research Article

\title{
Coupling Effect of Eccentricity and Slenderness Ratios on RCFST Column Instability Modes
}

\author{
Chao Guo iD and Zhengran Lu (iD) \\ School of Civil Engineering, Shenyang Jianzhu Univ., No. 25, Hunnan Middle Road, Hunnan District, Shenyang 110168, \\ Liaoning, China \\ Correspondence should be addressed to Zhengran Lu; luzhengranglovel@126.com
}

Received 21 July 2021; Accepted 15 October 2021; Published 27 October 2021

Academic Editor: Piero Colajanni

Copyright $(92021$ Chao Guo and Zhengran Lu. This is an open access article distributed under the Creative Commons Attribution License, which permits unrestricted use, distribution, and reproduction in any medium, provided the original work is properly cited.

\begin{abstract}
The instability damage modes of rectangle concrete-filled steel tube (RCFST) columns that are subjected to eccentric compression can be divided into two types based on the modified Jezek analytical procedure, namely, the eccentricity ratio $(\gamma)$ and the slenderness ratio $(\lambda)$ coupling effect. The RCFST columns have unilateral compression yield failure mode when $\gamma$ is small. However, it has compressive and tensile mode on both sides when the value of $\gamma$ is large. In this work, parametric analyses were performed to test 32 RCFST long columns by varying $\gamma$ with different $\lambda$ combinations. From the analysis, it was found that the results of the theoretical analysis of the load-tension strain $(P-\varepsilon)$ responses and the instability modes of the RCFST long columns are similar to the experimental results. Further, the proposed analytical method aids in better understanding the effects of $\gamma$ and $\lambda$ coupling on the stability behavior of the RCFST columns.
\end{abstract}

\section{Introduction}

The rectangle concrete-filled steel tube (RCFST) significantly improves the strength of long columns and reduces the section area of the columns [1]. However, it does not provide a full restraint effect of the steel tubes on the concrete core columns (CCC) as seen in the circular steel tube-confined concrete [2]. Further, under the action of compression and bending loads, the rectangular steel tube is prone to have local buckling in the middle part which transforms CCC into a plain concrete [3]. Moreover, the compression and bending stability of the RCFST long columns is a nonlinear problem under the cross control of the eccentricity ratio $(\gamma)$, the slenderness ratio $(\lambda)$, and the column end constraints [4]. Under these conditions of local buckling of a steel tube and a loss of constraint of CCC, the strength of long columns decreases sharply [5]. Therefore, it is necessary to conduct an in-depth analysis of the instability modes of RCFST to explore the influence of $\gamma$ and $\lambda$ on RCFST [6]. Further, the plane static instability modes of the RCFST long column should be analyzed emphatically [7]. According to the Euler critical load principle, the critical stability conditions of the RCFST long columns were determined by the elastic modulus, the moment of inertia, and the length [8]. However, the peak-load values of the codes EC4 [9], AISC 360 [10], and GB 50936 [11] were calculated assuming that the elastic modulus and the moment of inertia of the concrete and the steel were unified values by ignoring the difference between these two materials. Even though the composite theory takes into account the contributions of the steel tubes and the concrete to the critical load of the RCFST long columns separately, it is also required that the steel tubes and CCC shall bear the load simultaneously [12]. However, in the actual instability process of the RCFST long columns, the steel and the concrete cannot bear the load jointly. Further, the yield strain $\left(\varepsilon_{p}\right)$ of the steel is 0.002 when the compressive strain $\left(\varepsilon_{c c}\right)$ of the concrete is 0.0033 . However, the tensile strain $\left(\varepsilon_{c t}\right)$ of the concrete is only 0.0007 [13]. When the RCFST long columns undergo bending deformation, the CCC debond from the steel tubes and enter the failure stage before the steel tubes and then lose the bearing function [14]. However, the instability modes of the 
RCFST columns are more complicated with various defects $[7,15]$. The abovementioned instability modes of the RCFST long columns were verified by the many tests and numerical analysis.

Li et al. [16, 17] conducted an experimental and numerical parametric analysis according to 32 sets of highstrength RCFST long columns with $\gamma=0.13,0.23,0.33$, and 0.43 , respectively, with different $\lambda$ coupling effects on the RCFST column load-lateral displacement $(P-\Delta)$ responses. The instability damage processes on these samples and the RCFST columns instability modes were deduced. Many researchers conducted a lot of research on the instability modes of CFST columns in various methods [18-20]. Fei et al. [21] studied the behavior of multicell concrete-filled steel tube columns under eccentric loading using seven groups of model tests and inversed the compressive and tensile instability mode of RCFST columns. According to the different contribution of steel tube on each side to the bearing capacity of RCFST columns in the process of inplane instability damage mode, 12 groups of parametric tests and numerical simulation analysis of RCFST columns with unequal wall thickness were carried out by Guangyuan et al. [22], and it was proposed that this kind of RCFST is more suitable when $\lambda$ is relatively large and when $\gamma$ is greater than 0.2. Lei et al. [23] utilized eleven specimens of compression concrete-filled narrow rectangular steel tube (CFNRST) members, considering the variation of $\gamma$, and $\lambda$ of the cross section was subjected to combined compression and uniaxial bending on the weak axis. The transition process of the internal stress state of the RCFST long columns was very complex. Therefore, a theoretical analysis theory was needed to reveal the contribution of $\gamma$ and $\lambda$ of RCFST long columns in the instability modes [24].

To address this issue, in this work, the 32 RCFST specimens' load-tension strain $(P-\varepsilon)$ relationships and the compressive and tensile strain of the steel tube were analyzed. Initially, the two main instability modes, namely, the unilateral compression and bilateral compression tension of RCFST long columns with various $\gamma$ and $\lambda$ were obtained. Subsequently, the implicit function equations of two main instability modes were established based on the modified Jezek analytical method, and the regularization slenderness ratio $(\bar{\lambda})$ was introduced to conduct the elastoplastic theoretical analysis so that the two main instability modes could be expressed scientifically and reasonably in a dimensionless normalized form. In this way, the great difference of column length and section size of RCFST long columns was avoided, and the application scope of the analytical method was extended. Finally, a parametric analysis of the coupling effects of $\gamma$ and $\lambda$ on the instability modes of the RCFST long column system was conducted on 32 specimens of the RCFST long columns using the Maple program to verify the reliability of the theoretical analysis method.

\section{Experimental Analysis}

The details of the experimental analysis such as specifications of the specimen, test materials used, and the results are presented below.
2.1. Specimen Specifications. To study the influences of the slenderness ratios $(\lambda=23.09-46.19)$ and the eccentricity ratios $\left(\gamma=e_{0} / B=0.13-0.43\right)$ on the behaviors of the RCFST columns, a total of 32 (16 groups) experimental specimens with various lengths $(L=450-2000 \mathrm{~mm})$ and eccentric distances $\left(e_{0}=20-65 \mathrm{~mm}\right)$ were used for experimental analysis $[16,17]$. The detailed parameters are tabulated in Table 1 , where $\lambda=2 \sqrt{3} L / B[25,26]$. Further, the outer width $(B)$ and the thickness $(t)$ of the square steel tube were taken as $150 \mathrm{~mm}$ and $4 \mathrm{~mm}$, respectively. The test setup and specimen details are shown in Figure 1. The unit of the stiffener in Figure 1 (a) is in $\mathrm{mm}$. When $\mathrm{L}=450 \mathrm{~mm}$, a smaller value of $30 \mathrm{~mm}$ and $80 \mathrm{~mm}$ was taken, otherwise a larger value of $70 \mathrm{~mm}$ and $150 \mathrm{~mm}$ was considered. Figures 1(b) and 1(d) represent the stress state of the small and large eccentric compressions of the RCFST columns, respectively, and Figure 1(c) represents the number of strain gauges (SG) and surfaces (S) at the central section of the RCFST columns. In this work, S2 and S4 denote the compressive (concave) and tensile (convex) sides of the columns, respectively.

2.2. Test Materials. The trilinear $\sigma-\varepsilon$ model that was developed for the steel tubes with effective strengths in the range of $200-800 \mathrm{MPa}$ by $\mathrm{Han}$ et al. [27] was used in this work. The model is shown in Figure 2.

In Figure $2, f_{s y}$ and $f_{s u}$ refer to the yield and the ultimate strengths of the steel tube, respectively. $E_{s}$ refers to the elastic modulus at the initial point on the $\sigma-\varepsilon$ line and is taken as $206 \mathrm{GPa} . \varepsilon_{s p}$ refers to the strain at the strain hardening site, $\varepsilon_{s u}$ refers to the ultimate strain corresponding to the ultimate strength, $\varepsilon_{s y}$ refers to the yield strain that is defined as $\varepsilon_{s y}=f_{s y} / E_{s}$, and $E_{s p}$ refers to the initial elasticity modulus at the strain hardening point which is considered to be $0.02 E_{s}$. The steel tensile test curve that was presented by Li et al. $[16,17]$ conforms to the constitutive model proposed by Han et al. [27]. Therefore, the high-strength concrete cubic compression strength $\left(f_{c k}\right)$ values determined by Li were considered for the experimental specimens. The material parameters of the RSTCC specimens $[16,17]$ are presented in Table 2.

2.3. Test Results and Discussions. In this work, the statistical analysis of the strain gauge 15 (SG15), on the surface 4 (S4) of the steel tube on the tension side, and the strain gauge 7 (SG7) on the surface 2 (S2) of the steel tube on the compression side are focused as shown in Figure 1(c). The outer envelopes of the load-strain $(P-\varepsilon)$ relationships of the RCFST column under the eccentric compressive load are shown in Figure 3 for different values of $\gamma$ and $\lambda$. From the analysis, it was found that, as the value of $\gamma$ increases, the peak value of $P$ decreases rapidly, and the $P$ - $\varepsilon$ relationship of the RCFST systems showed a linear to nonlinear material behavior up to the peak response. Thereafter, there was a slight parabolic softening phase. During the follow-up process, the value of $P$ decreased slowly showing the characteristics of high ductility. However, when the values of $\gamma$ were very high $(0.43)$ 
TABle 1: Parameters of 32 RCFST columns.

\begin{tabular}{|c|c|c|c|c|c|c|c|c|c|}
\hline No. & Specimen & $L(\mathrm{~mm})$ & $\lambda$ & $\gamma$ & $P_{u 1}(\mathrm{kN})$ & $P_{u 2}(\mathrm{kN})$ & $P_{\text {ucal }}(\mathrm{kN})$ & Err. (\%) & Ref. \\
\hline 1 & EC1-1/2 & 450 & 10.4 & 0.13 & 2114 & 2130 & 2300 & 8.4 & {$[17]$} \\
\hline 2 & EC2-1/2 & 450 & 10.4 & 0.23 & 1846 & 1717 & 1939 & 8.8 & [17] \\
\hline 3 & EC3-1/2 & 450 & 10.4 & 0.33 & 1561 & 1455 & 1490 & 1.2 & [17] \\
\hline 4 & EC4-1/2 & 450 & 10.4 & 0.43 & 1265 & 1244 & 1324 & 5.5 & [17] \\
\hline 5 & LEC1-1/2 & 1000 & 23.1 & 0.13 & 2097 & 2200 & 2142 & 0.3 & [16] \\
\hline 6 & LEC2-1/2 & 1000 & 23.1 & 0.23 & 1679 & 1660 & 1780 & 6.6 & [16] \\
\hline 7 & LEC3-1/2 & 1000 & 23.1 & 0.33 & 1360 & 1413 & 1331 & 4 & [16] \\
\hline 8 & LEC4-1/2 & 1000 & 23.1 & 0.43 & 1176 & 1121 & 1090 & 5.1 & [16] \\
\hline 9 & LEC5-1/2 & 1500 & 34.6 & 0.13 & 2012 & 2113 & 2015 & 2.3 & [16] \\
\hline 10 & LEC6-1/2 & 1500 & 34.6 & 0.23 & 1617 & 1546 & 1645 & 4 & [16] \\
\hline 11 & LEC7-1/2 & 1500 & 34.6 & 0.33 & 1319 & 1310 & 1301 & 1 & [16] \\
\hline 12 & LEC8-1/2 & 1500 & 34.6 & 0.43 & 1081 & 1105 & 1083 & 0.9 & [16] \\
\hline 13 & LEC9-1/2 & 2000 & 46.2 & 0.13 & 1853 & 1848 & 1860 & 0.5 & [16] \\
\hline 14 & LEC10-1/2 & 2000 & 46.2 & 0.23 & 1545 & 1439 & 1505 & 0.9 & [16] \\
\hline 15 & LEC11-1/2 & 2000 & 46.2 & 0.33 & 1225 & 1175 & 1120 & 6.7 & [16] \\
\hline 16 & LEC12-1/2 & 2000 & 46.2 & 0.43 & 982 & 1004 & 986 & 0.7 & [16] \\
\hline
\end{tabular}

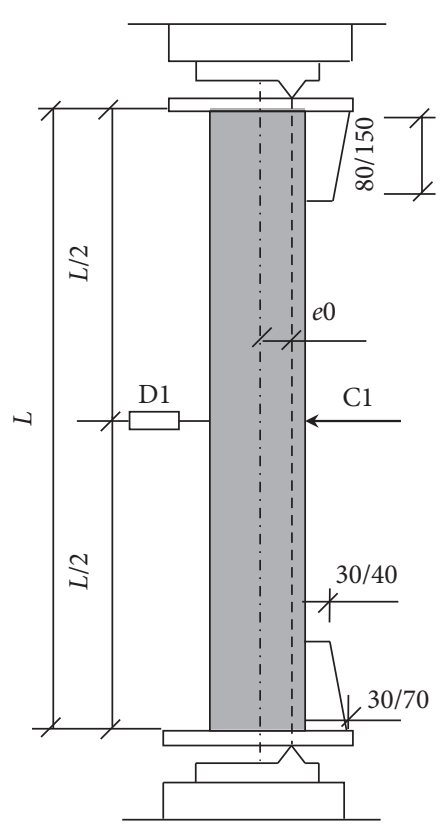

(a)
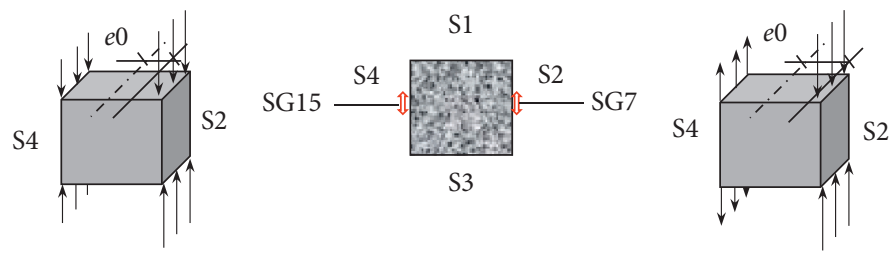

(c) (d)

FIGURE 1: Test setup and stress state: (a) specimen information, (b) small $\gamma$ stress state, (c) strain gauges (SG) arrangement, and (d) large $\gamma$ stress state.

corresponding to the extreme case assumed in this study, the $P-\varepsilon$ linear relationship no longer existed and this RCFST long column became similar to a pure bending member.

Figure 3 shows the curves of C_up/C_low (compressive state up/low limit line) and T_up/T_low (tensile state up/low limit line).

Further, based on the SG15 variations, the tension (S4) regional working states and the compression (SG7) working states under the peak-load conditions were categorized into unilateral compression instability and compressions and yield states, although there were four types in $[16,17]$. In the case of unilateral compression instability of the RCFST specimens with a relatively small $\gamma$ and a low $\lambda$ as shown in Figures 3(a) and 3(b), the value of SG7 at $P_{u}$ was found to be negative and smaller than $\varepsilon_{y}$. Meanwhile, the value of SG15 was found to be larger than $\varepsilon_{y}$. This shows that the steel tube and the CCC are in a state of collaborative stress, and the RCFST column is in unilateral compression unstable state. In the case of compression and tension yield states, it was found that, for large $\gamma$, the respective SG15 values corresponding to $P_{u}$ were greater than or equal to $\varepsilon_{y}$ (Figures $3(\mathrm{c})$ and $3(\mathrm{~d})$ ). Hence, it was concluded that the tension regional steel tubes were in the plastic tension state. During this time, the S2 of the steel tube yielded under compression and S4 


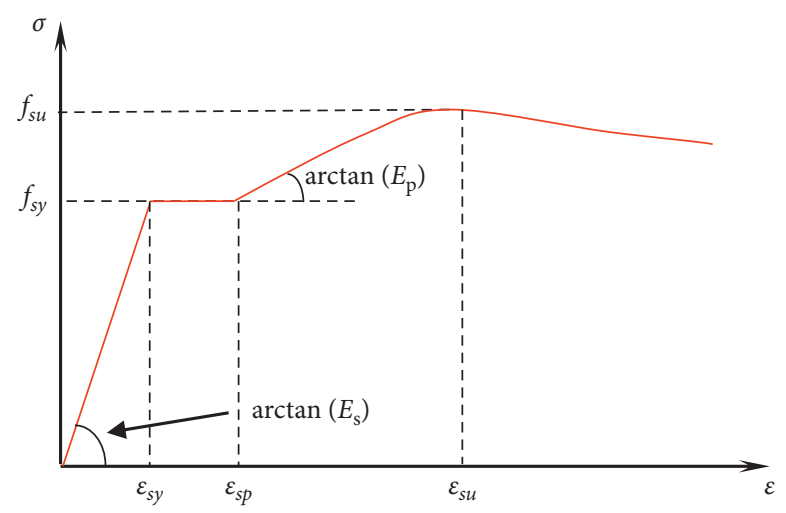

Figure 2: Model for steel tube properties (Figure 2 is reproduced from Zhengran Lu et al. 2021).

TABLE 2: Material parameters of RSTCC long column specimens.

\begin{tabular}{lcccccc}
\hline Phase & $E(\mathrm{GPa})$ & $\mu$ & $\begin{array}{c}f_{c k} \\
(\mathrm{MPa})\end{array}$ & $\begin{array}{c}f_{s y} \\
(\mathrm{MPa})\end{array}$ & $\begin{array}{c}f_{s u} \\
(\mathrm{MPa})\end{array}$ & Ref \\
\hline $\begin{array}{l}\text { Concrete } \\
\text { Steel tube }\end{array}$ & 41.8 & 0.2 & 110.5 & & & {$[16,17]$} \\
\hline
\end{tabular}

E: elastic model, $\mu$ : Poisson's ratio, and $f_{c k}$ : concrete compressive strength.

yielded under tension. Further, the RCFST was in both sides yield instability mode. Therefore, the steel tube and concrete were unable to work simultaneously.

\section{Analytical Method of RCFST Column Instability}

During the mechanical analysis, the experimental results showed that the strength $\left(P_{u}\right)$ and the stability of the RCFST columns were affected by $\gamma$ and $\lambda$ coupling control. According to whether the steel tube on the tension side of the RCFST column was in a yield state during the instability process, the instability modes of the RCFST column were divided into the following two types, as shown in Figure 4(A) and $4(\mathrm{~B})$.

Based on a large number of experiments and numerical analysis [28-31], the instability process of the RCFST columns were deduced as follows: initially, under the coupling action of axial load and bending moment, the fiber at the compression edge of the cross section of the RCFST column began to yield, gradually from elastic to plastic working state. Then, as the coupling effects increased, it was found that the elastic region of the cross section shrank the bending stiffness of the RCFST column decreased, and the buckling deformation accelerated rapidly. Thus, it resulted in a rapid increase of additional bending moments. Further, when the increasing value of the bending capacity of the RCFST column was less than the increasing value of the external coupling action, the internal and external forces in the cross section of the RCFST column could not be balanced, which lead to instability.

Moreover, the ultimate load $P_{u}$ of the RCFST column was calculated according to the instability process. Furthermore, under a stable condition, the RCFST column was found to yield from the edge fiber of the cross section with the largest bending moment and developed along the depth direction.

From the results, it was found that both $\gamma$ and $\lambda$ had a significant influence on the RCFST column stability modes. Further, from $\gamma=e_{0} / h$ and $\lambda=2 \sqrt{3} \mathrm{l} / \mathrm{h}$, it was concluded that $\lambda$ and $\gamma$ affected the interaction. Moreover, it was observed that when $\gamma$ and $\lambda$ were both small, the plastic yield development range was limited to the shaded part in Figure 4(A.c) and was constrained to the compression side. Further, when either $\gamma$ or $\lambda$ was larger, a plastic yield zone was found to appear on both sides of the compression and tension as shown in Figure 4(B.c). To analyze the influence of $\gamma$ and $\lambda$ coupling on the stability of the RCFST column, the modified Jezek analytical method was used to calculate the stability of the RCFST column under eccentric compression using the boundary conditions as hinged at both ends which are described in the following section.

3.1. Modified Jezek Analytical Method. Based on the theory of the modified Jezek analytical method [32], the following assumptions were made: (1) the elastoplastic constitutive models for the steel tube and the CCC in the RCFST column were adopted in this paper. Further, the steel tube and the CCC bear the compressive stress together under compression, while only the steel tube bears the tensile stress under tensile yield as the CCC could not bear the tensile stress. (2) The deformation curve of the RCFST column under eccentric load was a half-wave of sine curve as shown in Figure 4(b). In this work, 32 groups of eccentrically loaded RCFST column samples $[16,17]$ were simplified as biaxial symmetric rectangular section compression and bending members, whose two ends were hinged, and the sectional area was $A=b h$. Further, under the coupling action of an axial pressure $P$ and end bending moment $M$, two kinds of elastic-plastic instability modes were observed as shown in Figures 4(A) and $4(\mathrm{~B})$.

Furthermore, it was observed that, for the RCFST column, samples with small $\gamma$ yielded only in the compression zone, and the height of the elastic zone of the central cross section was $h_{e}$, as shown in Figure 4(A.c). Moreover, when the samples had large $\gamma$, the steel tube in 


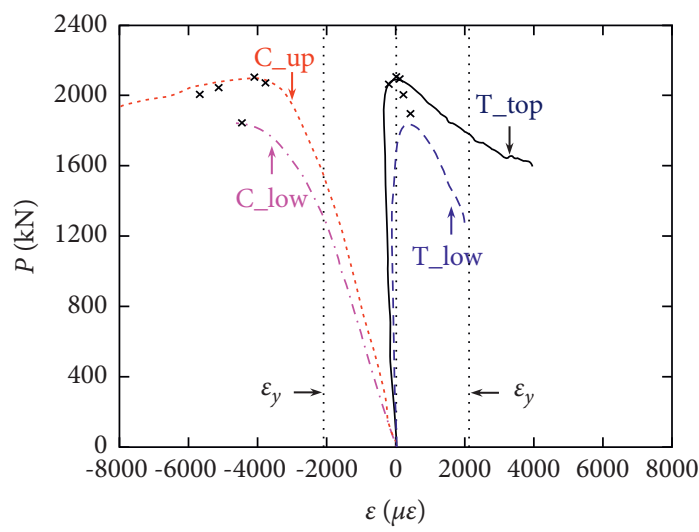

(a)

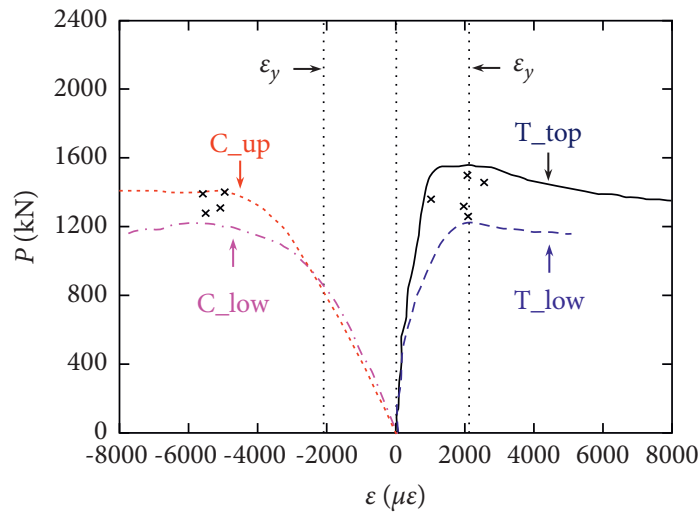

(c)

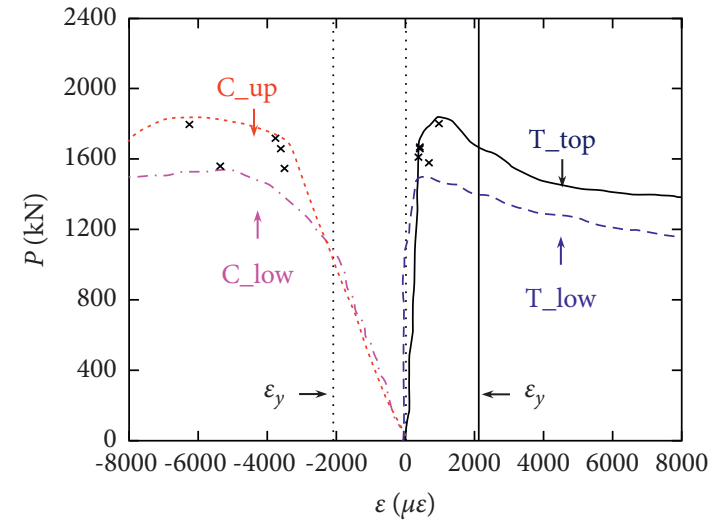

(b)

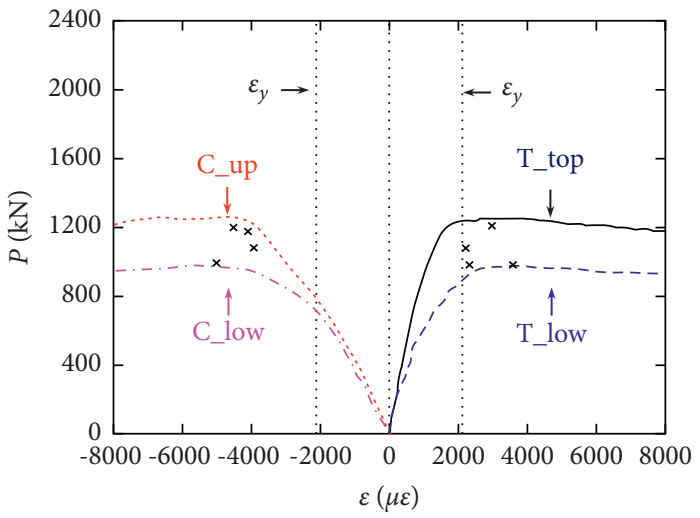

(d)

Figure 3: Steel tube $P-\varepsilon$ curve: (a) $\gamma=0.13$, (b) $\gamma=0.23$, (c) $\gamma=0.33$, and (d) $\gamma=0.43$.

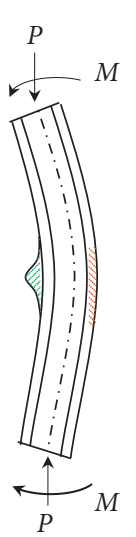

(a)

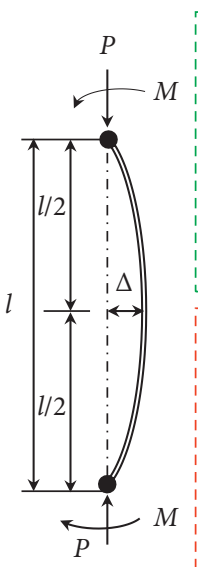

(b)

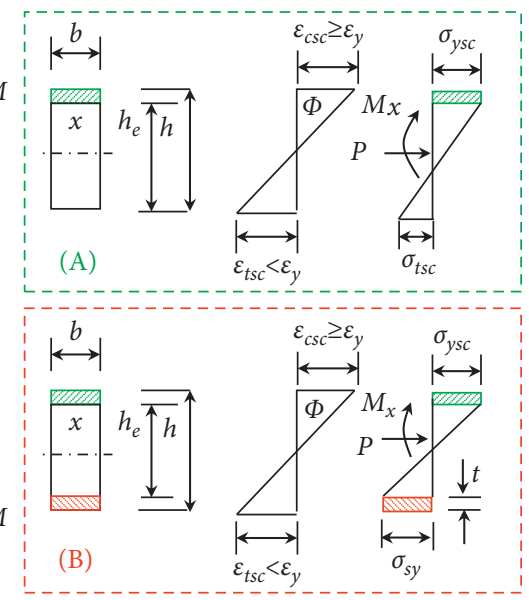

(c) (d)

FIGURE 4: Instability modes of the RCFST column: (A) unilateral compression and (B) both sides yield instability modes. (a) Instability phenomenon, (b) deformation curve, (c) cross section parameter, (d) strain state, and (e) stress state.

the tension zone was found to reach the yield strength $f_{s y}$ while the compression zone was found to reach the yield strength, and the elastic zone shrank to the middle of the section, as shown in Figure 4(B.c).

According to the above two different instability modes of the RCFST columns, the load and the moment balance equations of the middle height cross section were established, and the $P-\Delta$ relationship was obtained. Then, the critical load $P_{u}$ was obtained by using the extreme value condition as $\mathrm{d} P / \mathrm{d} \Delta=0$.

Further, the critical elastic load $\left(P_{E}\right)$ of the RCFST long columns are suggested [33], as given in equations (1)-(9): 


$$
\begin{aligned}
P_{E} & =\frac{\pi^{2} E_{s c} A_{s c}}{\lambda^{2}} \\
E_{s c} & =\frac{f_{s c p}}{\varepsilon_{s c p}} \\
f_{s c p} & =\left(0.0717 \cdot \frac{f_{s y}}{f_{s c, 235}}+0.4513 \cdot \frac{f_{c k, C 30}}{f_{c k}}+0.4955\right) \cdot f_{s c y} \\
\varepsilon_{s c p} & =3.8437 \times 10^{-6} \cdot f_{s y}, \\
f_{s c p} & =\left(1.212+B \cdot \xi+C \cdot \xi^{2}\right) \cdot f_{c k} \\
B & =0.1521 \cdot \frac{f_{s y}}{f_{c k, C 30}}+0.8421 \\
C & =-0.0915 \cdot \frac{f_{s y}}{f_{c k, C 30}}+0.0272 \\
\xi & =\frac{A_{s} f_{s y}}{A_{c} f_{c k}} . \\
f_{s y, 235} & =235 \mathrm{MPa}, \\
f_{c k, 235} & =20.318 \mathrm{MPa},
\end{aligned}
$$

3.2. RCFST Column under Unilateral Compression Instability Mode. Figure 4(A.d) shows the strain distribution diagram of the middle height section of the RCFST column under small eccentric compression, and the corresponding stress distribution is shown in Figure 4 (A.e). $P_{y}$ refers to the plastic yieldbearing load of the RCFST column under axial compression and is given as shown in the following equation:

$$
P_{y}=\sigma_{y s c} A \text {. }
$$

The load balance conditions of the section at the middle height of the column are obtained based on the following equations:

$$
\begin{aligned}
P & =P_{y}-\frac{1}{2}\left(\sigma_{y s c}+\sigma_{t s c}\right) \mathrm{bh}_{e}, \\
\sigma_{y s c}+\sigma_{t s c} & =\frac{2\left(P_{y}-P\right)}{\mathrm{bh}_{e}} .
\end{aligned}
$$

The moment balance condition of the section at the middle height is obtained as shown in the following equation:

$$
M+P \Delta=\frac{1}{2}\left(\sigma_{y s c}+\sigma_{t s c}\right) b_{e}\left(\frac{h}{2}-\frac{h_{e}}{3}\right) .
$$

From equations (12) and (13), the value of $h_{e}$ is obtained as shown in the following equation:

$$
h_{e}=\frac{3 h}{2}-\frac{3(M+P \Delta)}{P_{y}-P} \text {. }
$$

The curvature of the middle height section $(\Phi)$ is obtained as shown in the following equation:

$$
\Phi=\frac{\varepsilon_{y s c}+\varepsilon_{t s c}}{h_{e}}=\frac{\sigma_{y s c}+\sigma_{t s c}}{E_{s c} h_{e}}=\frac{2\left(P_{y}-P\right)}{E_{s c} \mathrm{bh}_{\mathrm{e}}^{2}} .
$$

According to the second assumption of the modified Jezek analytical method, the deflection curve of the RCFST column was defined as shown in the following equation:

$$
y=\Delta \sin \frac{\pi x}{l}
$$

From the definition of $\Phi$, it can be concluded as shown in the following equation:

$$
\Phi=-y^{\prime \prime}\left(\frac{l}{2}\right)=\frac{\Delta \pi^{2}}{l^{2}}=\frac{2\left(P_{y}-P\right)}{E_{s c} \mathrm{bh}_{\mathrm{e}}^{2}} .
$$

By combining equations (14) with (17), the internal and external stresses of the middle height cross section are balanced, and the deformation compatibility condition is transformed into $P-\Delta$ relationships as shown in the following equation:

$$
\Delta\left(\frac{h}{2}\left(1-\frac{P}{P_{y}}\right)-\frac{M+P \Delta}{P_{y}}\right)^{2}=\frac{2 l^{2} P_{y}}{9 b \pi^{2} E_{s c}}\left(1-\frac{P}{P_{y}}\right)^{3} .
$$

From the critical equilibrium condition $\mathrm{d} P / \mathrm{d} \Delta=0$, it is found that

$$
\Delta=\frac{P_{y}}{3 P}\left(\frac{h}{2}\left(1-\frac{P}{P_{y}}\right)-\frac{M}{P_{y}}\right) .
$$

By combining equations (19) with (18), the peak value of eccentric compressive strength $\left(P_{u}\right)$ is obtained as shown in the following equation:

$$
P_{u}=\frac{\mathrm{bh}^{3} \pi^{2} E_{s c}}{12 l^{2}}\left(1-\frac{2 M}{h P_{y}\left(1-\left(P_{u} / P_{y}\right)\right)}\right)^{3} .
$$

In equation (20), $M=P_{u} e_{0}$.

In the derivation of equations (11) to (20), the calculated value of $P_{E}$ in the RCFST column in equation (1) is not applied; however, the RCFST is analyzed as an elasticplastic material similar to steel. This assumption leads to the calculation error of deviation between the calculated results and the material properties of the RCFST. To solve this problem, the following corrections are necessary which are suitable for the calculation of the actual RCFST column.

In this work, it was assumed that $\alpha=P_{u} / P_{y}$, and $P_{E 0}=$ $\pi^{2} E_{s c} \mathrm{bh}^{3} / 12 l^{2}$ is Euler critical stress of long column. Further, the ideal elastic-plastic constitutive relation of steel was modified by using $\lambda$ of the RCFST with equation (1) to replace $P_{E 0}$ in equation (20) and $P_{u}$ was obtained as shown in the following equation: 


$$
P_{u}=P_{E}\left(1-\frac{2 M}{\mathrm{hP}_{y}(1-\alpha)}\right)^{3} .
$$

Since $M$ in equation (21) is also a function of $P_{u}$, equation (21) had no explicit solution and had to be solved using the Newton interpolation method.

Further, $\lambda$ was regularized as $\bar{\lambda}^{2}=P_{y} / P_{E}$ [34], and equation (21) was reduced to the following equation:

$$
\alpha \bar{\lambda}^{2}=\left(1-\frac{2 \alpha \gamma}{(1-\alpha)}\right)^{3}
$$

According to equation (22), $\bar{\lambda}$ was expressed as a polynomial of $\gamma$ after regularization. The above equations were established based on the conditions of $\sigma_{t s c} \leq f_{s c p}$ and $h_{e}>1-\alpha$.

From equations (14) and (21), it was concluded as shown in the following equations:

$$
\begin{aligned}
\frac{h_{e}}{h} & =1-\frac{2 \alpha \gamma}{(1-\alpha)}>1-\alpha, \\
\gamma & <\frac{1-\alpha}{2} .
\end{aligned}
$$

3.3. RCFST Column under Compression and Tension Yield Instability Modes on Both Sides. In this analysis, the RCFST column was subjected to both compression and tension yield instability modes on both sides of the specimen. The steel tube tension was expressed as shown in the following equation:

$$
T=f_{s y} \text { bt. }
$$

The balance conditions of the internal and external stresses were calculated as shown in the following equations:

$$
\begin{aligned}
P-T & =P_{y}-\frac{1}{2}\left(\sigma_{y s c}+\sigma_{t s c}\right) \mathrm{bh}_{e}, \\
\sigma_{y s c}+\sigma_{t s c} & =\frac{2\left(P_{y}-P+T\right)}{\mathrm{bh}_{e}} .
\end{aligned}
$$

From the moment balance condition, it was concluded as shown in the following equation:

$$
M+P \Delta=\frac{\mathrm{Th}}{2}+\frac{1}{2}\left(\sigma_{y s c}+\sigma_{t s c}\right) \mathrm{bh}_{e}\left(\frac{h}{2}-\frac{\mathrm{h}_{e}}{3}\right) .
$$

By substituting equation (27) into (28), the following equation was obtained:

$$
M+P \Delta=\frac{\mathrm{Th}}{2}+\left(P_{y}-P+T\right)\left(\frac{h}{2}-\frac{\mathrm{h}_{e}}{3}\right) .
$$

From equation (29), the expression of $h_{\mathrm{e}}$ was obtained as shown in the following equation:

$$
\mathrm{h}_{e}=\frac{3 h}{2}-\frac{6 M+6 P \Delta-3 \mathrm{Th}}{2\left(P_{y}-P+T\right)} .
$$

Further, the curvature of the middle height section $(\Phi)$ was obtained as shown in the following equation:

$$
\Phi=-y^{\prime \prime}\left(\frac{l}{2}\right)=\frac{\Delta \pi^{2}}{l^{2}}=\frac{\varepsilon_{y s c}+\varepsilon_{t s c}}{h_{e}}=\frac{\sigma_{y s c}+\sigma_{t s c}}{E_{s c} h_{e}}=\frac{2\left(P_{y}-P+T\right)}{E_{s c} h_{\mathrm{e}}^{2}} .
$$

By substituting equation (30) into (31), the relationship of $P-\Delta$ was obtained as shown in the following equation:

$$
\Delta\left(\frac{h}{2}\left(1-\frac{P}{P_{y}}\right)-\frac{M+P \Delta+\mathrm{Th}}{P_{y}}\right)^{2}=\frac{2 l^{2} P_{y}}{9 \pi^{2} b E_{s c}}\left(1-\frac{P+T}{P_{y}}\right)^{3} .
$$

From the critical equilibrium condition $\mathrm{d} P / \mathrm{d} \Delta=0, \Delta$ was obtained as shown in the following equation:

$$
\Delta=\frac{P_{y}}{3 P}\left(\frac{h}{2}\left(1-\frac{P}{P_{y}}\right)-\frac{M+\mathrm{Th}}{P_{y}}\right) .
$$

By substituting into equation (32), it can be concluded as shown in the following equation:

$$
P_{u}=P_{E}\left(1-\frac{2 M+\mathrm{Th}}{\mathrm{hP}_{y}\left(1-\left(P / P_{y}\right)-\left(P / P_{y}\right)\right)}\right)^{3} .
$$

Assuming that $T / P_{y}=\eta$, equation (34) was reduced to the following equation:

$$
\alpha \bar{\lambda}^{2}=\left(1-\frac{2 \alpha \gamma+\eta}{1-\alpha-\eta}\right)^{3}
$$

The above equations were established under the conditions of $\sigma_{t s c} \geq \sigma_{t s c}$ and $h_{e} / h \leq 1-\alpha$.

From equation (30), we know that

$$
\frac{h_{e}}{h} \leq 1-\alpha+\eta \text {. }
$$

When equations (30) and (33) were substituted into equation (36), the following results were obtained as shown in the following equation:

$$
\alpha \geq 1-(1-\alpha+\eta)^{2}-2 \alpha \gamma+2 \eta
$$

Due to the complexity of the above reasoning process, the intermediate calculation results of the process were expressed in the form of a diagram, as shown in Figure 5. In Figure 5, the horizontal axis represents the horizontal deflection $(\Delta)$ at the middle height section of the RCFST column, and the longitudinal axis represents the strength $(P)$ under various assumptions. The distance from $o$ to o' represents the initial eccentricity $e_{0}$. The gradient of the line represents the initial elastic modulus $\left(E_{s c}\right)$ of the RCFST. The top point $\left(P_{E 0}, \Delta_{E 0}\right)$ represents the Euler critical stress of the RCFST column under the assumptions of the steel tube and the CCC as a kind of unified ideal elastic-plastic material.

Further, $\left(P_{E}, \Delta_{E}\right)$ represents the Euler critical stress corrected by $\lambda$. $\left(P_{y}, \Delta_{y}\right)$ represents the compressive strength of the RCFST column at plastic yield. $\left(P_{e}, \Delta_{e}\right)$ represents the strength of the initial elastic stage. $\left(P_{u}, \Delta_{u}\right)$ represents the calculated compressive strength of the two instability modes proposed in this paper. The curve represents the experimental curve of $[17,18]$. From the 


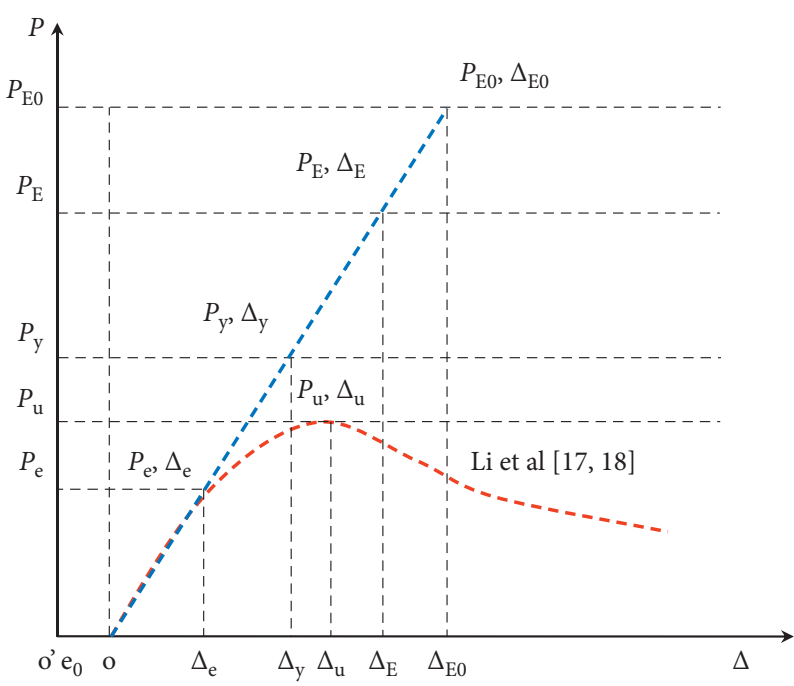

FIgURE 5: Instability mode calculation process.

position height relationship of the above points, it is observed that the Eulerian critical stress $P_{E 0}$ under the ideal elastic-plastic instability mode was the highest, while $P_{E}$ after $\lambda$ correction reflecting the characteristics of RCFST composite material was lower than $P_{E 0}$. Furthermore, the compressive strength $P_{y}$ that was calculated by area weighting was smaller than $P_{E}$ according to the plastic yield strength of the steel tube and the concrete. The actual ultimate compressive strength $P_{u}$ of the RCFST was found to be between $P_{e}$ and $P_{y}$.

From Figure 5, it is also observed that the calculation method proposed in this paper can perfectly and scientifically explain the instability mode of the RCFST columns under eccentric compression by the coupling action of $\gamma$ and $\lambda$.

\section{Comparison of the Test Results}

As equations (21) and (34) were both implicit functions of $P_{u}$, based on Newton's interpolation method, the Maple program was used to calculate $P_{u}$ under two instability modes. The program flow is shown in Figure 6 [35].

The physical and mechanical indexes and the geometric parameters of the RCFST columns are shown in Tables 1 and 2.

The analytical results were compared with the samples of the RCFST columns under the coupling action of $\gamma$ and $\lambda$ in $[16,17]$. The results are shown in Figure 7 and Table 1. From the results, it was observed that the calculation formula and the program proposed in this paper ensured that the error between theoretical calculation results and

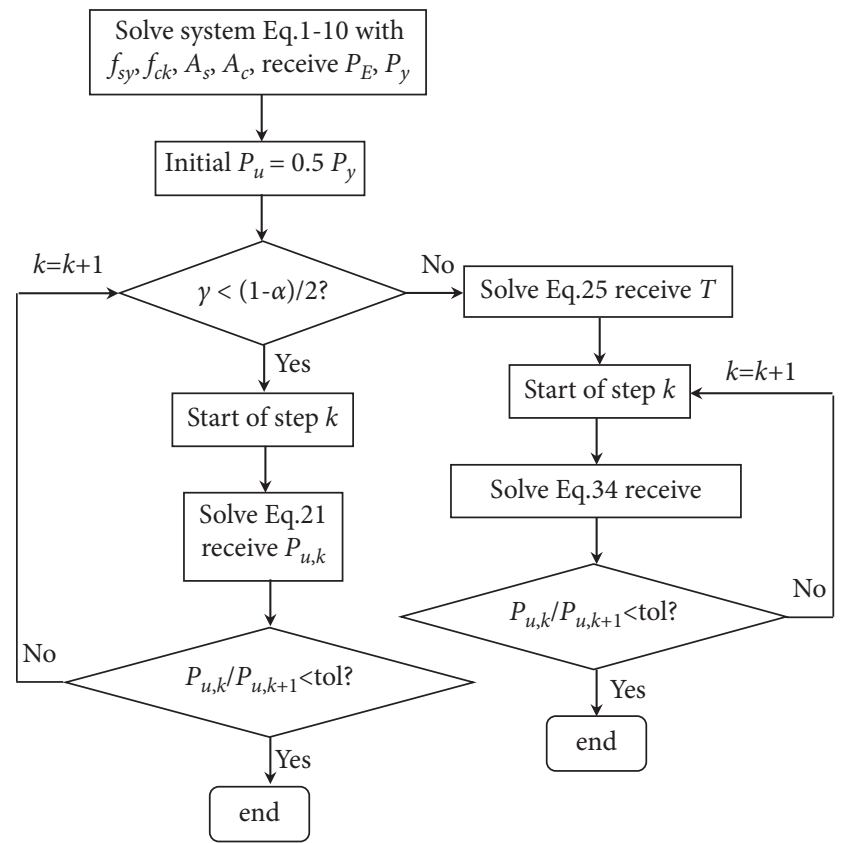

Figure 6: Maple program flowchart.

samples is within $10 \%$, and thereby met the needs of the detailed design of the RCFST column.

From equations (21) and (34), it was concluded that $P_{u}$ is related to the square of $\lambda$ and the cube of $\gamma$. Therefore, the influence of $\gamma$ on $P_{u}$ was found to be far greater than the weight of $\lambda$. This was verified by the analytical results in Table 1 and Figure 7. 


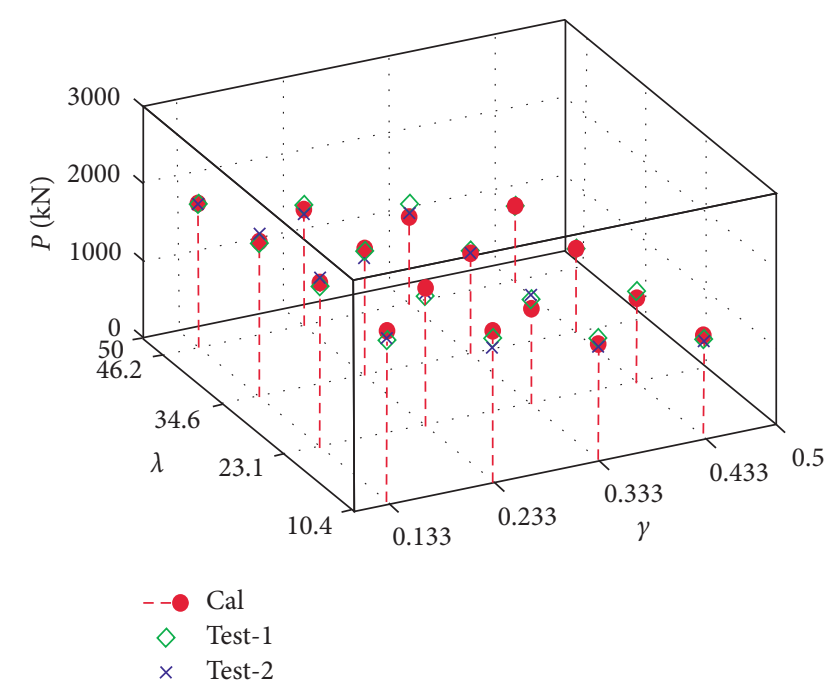

FIgURE 7: Comparison of sample and calculation results.

\section{Conclusions}

In this paper, the modified Jezek analytical method was developed using the Maple program to calculate the RCFST columns $P_{u}$. The RCFST column instability modes were divided into two types on the yield states of the steel tube tension side. Further, the corresponding $P-\varepsilon$ curve relationship was studied for each RCFST system. The following conclusions were drawn from the analytical method performed for the RCFST column systems:

(1) The effect of the $\gamma$ on the peak value of the $P-\varepsilon$ curve relationship of the RCFST long columns was more significant than that of $\lambda$. High $\gamma$ contributed to a more rapid decrease in the peak value of the $P-\varepsilon$ curve of the RCFST long columns during the compressive loading processes. This facilitated the RCFST long column systems to reach higher nonlinear characteristics before softening and lower residual strength after softening.

(2) The RCFST column instability modes were divided into two types based on the yielding of the tensile side of the steel tube under various $\gamma$. In the case of lower eccentricity, such as $\gamma=0.13$ and 0.23 , the instability modes of the RCFST long columns exhibited unilateral compression. However, at higher eccentricity, such as $\gamma=0.33$, and 0.43 , the instability modes of the RCFST long columns were both sides yield instability modes.

(3) The $\lambda$ calculated of the RCFST column was converted as a composite material, and the Euler critical stress that was calculated based on the ideal elastic-plastic body of steel was replaced by the composite material, which made the theoretical calculation of instability modes of the RCFST column possible.

(4) The ratio of the yield stress on the tensile side of the steel tabular to the plastic yield strength of the full section of the RCFST column was introduced, so that the two modes of instability of the RCFST column could be transformed into dimensionless normalization formula. This not only expanded the application scope of the Jezek analytical method in the calculation of the RCFST column instability but also ensured that the error of the above theoretical calculation was less than $10 \%$ by comparing with many groups of reference samples $[16,17]$.

\section{Data Availability}

All data, models, and code included in this study are available upon request by contact with the corresponding author.

\section{Conflicts of Interest}

The authors declare that they have no conflicts of interest.

\section{Acknowledgments}

This research was supported by Liaoning Revitalization Talents Program (no. XLYC1907121), Scientific Research Project of Liaoning Provincial Department of Education (nos. lnjc202019 and lnjc201904), and Province Natural Science Foundation of Liaoning, China (no. 2021-KF-1307).

\section{References}

[1] L.-H. Han, W. Li, and R. Bjorhovde, "Developments and advanced applications of concrete-filled steel tubular (CFST) structures: Members," Journal of Constructional Steel Research, vol. 100, pp. 211-228, 2014.

[2] L.-H. Han, Y.-J. Li, and F.-Y. Liao, "Concrete-filled double skin steel tubular (CFDST) columns subjected to long-term sustained loading," Thin-Walled Structures, vol. 49, no. 12, pp. 1534-1543, 2011.

[3] L.-H. Han, C. Hou, and Q.-L. Wang, "Square concrete filled steel tubular (CFST) members under loading and chloride corrosion: Experiments," Journal of Constructional Steel Research, vol. 71, no. 1, pp. 11-25, 2012.

[4] Y. F. Yang, L. H. Han, and X. Wu, "Concrete shrinkage and creep in recycled aggregate concrete-filled steel tubes," Advances in Structural Engineering, vol. 11, no. 4, pp. 383-396, 2008.

[5] Z. Tao and L.-H. Han, "Behaviour of fire-exposed concretefilled steel tubular beam columns repaired with CFRP wraps," Thin-Walled Structures, vol. 45, no. 1, pp. 63-76, 2007.

[6] H. Dong, Y. Li, W. Cao, Q. Qiao, and R. Li, "Uniaxial compression performance of rectangular CFST columns with different internal construction characteristics," Engineering Structures, vol. 176, pp. 763-775, 2018.

[7] C. Guo and Z.-R. Lu, "Effect of circumferential gap on dynamic performance of CFST arch bridges," Journal of Bridge Engineering, vol. 26, no. 2, Article ID 04020121, 2021.

[8] Y. Q. Huang, J. Y. Fu, A. R. Liu, Y. L. Pi, D. Wu, and W. Gao, "Effect of concrete creep on dynamic stability behavior of slender concrete-filled steel tubular column," Composites Part B: Engineering, vol. 157, pp. 173-181, 2019. 
[9] Eurocode 4, Design of Composite Steel and Concrete Structures-Part 1-1: General Rules and Rules for Buildings, European Committee for Standardization, Brussels, Belgium, 2004.

[10] American Institute of Steel Construction, ANSI/AISC 360-16, Specification for Structural Steel Buildings, American Institute of Steel Construction, Chicago, IL, USA, 2016.

[11] GB 50936-2014, Technical Code for Concrete Filled Steel Tube Structures, China Architecture \& Building Press, Beijing, China, 2014.

[12] Y.-X. Hua, L.-H. Han, Q.-L. Wang, and C. Hou, "Behaviour of square CFST beam-columns under combined sustained load and corrosion: Experiments," Thin-Walled Structures, vol. 136, pp. 353-366, 2019.

[13] Y. Y. Wang, Y. Geng, J. Chen, and M. Z. Zhao, "Testing and analysis on nonlinear creep behaviour of concrete-filled steel tubes with circular cross-section," Engineering Structures, vol. 185 , pp. 26-46, 2019.

[14] C. Guo and Z. Lu, "Effect of temperature on CFST arch bridge ribs in harsh weather environments," Mechanics of Advanced Materials and Structures, vol. 52, pp. 1-16, 2020.

[15] Z. Lu, C. Guo, and G. Li, "Air void and ring gap effect on CFST arch bridges dynamic performance," Journal of Constructional Steel Research, vol. 177, p. 106418, 2021.

[16] G.-C. Li, B.-W. Chen, Z.-J. Yang, Y.-P. Liu, and Y.-H. Feng, "Experimental and numerical behavior of eccentrically loaded square concrete-filled steel tubular long columns made of high-strength steel and concrete," Thin-Walled Structures, vol. 159, p. 107289, 2021.

[17] G. Li, B. Chen, Z. Yang, and Y. Feng, "Experimental and numerical behaviour of eccentrically loaded high strength concrete filled high strength square steel tube stub columns," Thin-Walled Structures, vol. 127, pp. 483-499, 2018.

[18] J. Moon, J. J. Kim, T.-H. Lee, and H.-E. Lee, "Prediction of axial load capacity of stub circular concrete-filled steel tube using fuzzy logic," Journal of Constructional Steel Research, vol. 101, pp. 184-191, 2014.

[19] M.-X. Xiong, D.-X. Xiong, and J. Y. R. Liew, "Behaviour of steel tubular members infilled with ultra high strength concrete," Journal of Constructional Steel Research, vol. 138, pp. 168-183, 2017.

[20] C. Guo, Z. Lu, and G. Li, "Multi-scale numerical analysis of the eccentricity on the instability of RCFST long columns," Thin-Walled Structures, vol. 167, pp. 108228-108316, 2021.

[21] F. Yin, W.-L. Cao, S.-D. Xue, H.-Y. Dong, and R.-W. Wang, "Behavior of multicell concrete-filled steel tube columns under eccentric loading," Journal of Constructional Steel Research, vol. 172, Article ID 106218, 2020.

[22] G. Fu, G.-Y. Fu, C.-J. Yu, S.-P. Li, F.-L. Wang, and J. Yang, "Behaviour of rectangular concrete-filled steel tube slender column with unequal wall thickness," Engineering Structures, vol. 236, Article ID 112100, 2021.

[23] L. Zhang, C.-X. Mao, L. Xiao-Gang, G.-S. Tong, T. Jing, and Y.-C. Wang, "Experimental study on CFNRST members under combined compression and bending," Journal of Constructional Steel Research, vol. 167, Article ID 105950, 2020.

[24] Y. Du, Z. Chen, J. Y. Richard Liew, and M.-X. Xiong, "Rectangular concrete-filled steel tubular beam-columns using high-strength steel: experiments and design," Journal of Constructional Steel Research, vol. 131, pp. 1-18, 2017.

[25] S. Zhang, L. Guo, Z. Ye, and Y. Wang, "Behavior of steel tube and confined high strength concrete for concrete-filled RHS tubes," Advances in Structural Engineering, vol. 8, no. 2, pp. 101-116, 2005.
[26] L.-H. Han and G.-H. Yao, "Experimental behaviour of thinwalled hollow structural steel (HSS) columns filled with selfconsolidating concrete (SCC)," Thin-Walled Structures, vol. 42, no. 9, pp. 1357-1377, 2004.

[27] L.-H. Han, G.-H. Yao, and Z. Tao, "Performance of concretefilled thin-walled steel tubes under pure torsion," Thin-Walled Structures, vol. 45, no. 1, pp. 24-36, 2007.

[28] T. Fujimoto, A. Mukai, I. Nishiyama, and K. Sakino, "Behavior of eccentrically loaded concrete-filled steel tubular columns," Journal of Structural Engineering, vol. 130, no. 2, pp. 203-212, 2004.

[29] Q. Q. Liang, V. I. Patel, and M. N. S. Hadi, "Biaxially loaded high-strength concrete-filled steel tubular slender beam-columns, Part I: multiscale simulation," Journal of Constructional Steel Research, vol. 75, pp. 64-71, 2012.

[30] V. I. Patel, Q. Q. Liang, and M. N. S. Hadi, "Biaxially loaded high-strength concrete-filled steel tubular slender beam-columns, part II: parametric study," Journal of Constructional Steel Research, vol. 110, pp. 200-207, 2015.

[31] X. Qu, Z. Chen, D. A. Nethercot, L. Gardner, and M. Theofanous, "Load-reversed push-out tests on rectangular CFST columns," Journal of Constructional Steel Research, vol. 81, pp. 35-43, 2013.

[32] C. C. Weng and C. P. Lin, "Study on maximum strength of cold-formed steel columns," Journal of Structural Engineering, vol. 118, pp. 128-146, 1992.

[33] L.-H. Han, G.-H. Yao, and X.-L. Zhao, "Behavior and calculation on concrete-filled steel CHS (Circular Hollow Section) beam-columns," Steel and Composite Structures, vol. 4, no. 3, pp. 169-188, 2004.

[34] J. M. Portolés, M. L. Romero, F. C. Filippou, and J. L. Bonet, "Simulation and design recommendations of eccentrically loaded slender concrete-filled tubular columns," Engineering Structures, vol. 33, no. 5, pp. 1576-1593, 2011.

[35] Y. Bouras and Z. Vrcelj, "Thermal in-plane stability of concrete-filled steel tubular arches," International Journal of Mechanical Sciences, vol. 163, Article ID 105130, 2019. 